Freudenberg has been able to suggest the formula for a portion of Spruce lignin. This formula is consistent with the chemistry and physical chemistry of the material and also corresponds to the possible biological growth of the naturally occurring lignin molecule.

A biological synthesis of the aromatic ring from carbohydrate molecules such as glucose occurs in plant and bacterial cells and is an extremely complex, interesting and significant biochemical topic. It is obviously important for the formation of lignin precursors. Work on this subject has been carried out using both radioactive tracer and enzyme techniques on plant tissues and bacteria. The overall scheme for the production of cinnamyl alcohol derivatives from carbohydrates is now firmly established.

One of the most obvious biological features of lignin is its occurrence during definite stages of the growth of the cell, and the sequential synthesis of the enzymes necessary for the production of coniferyl and the related alcohols therefore opens a very important field of study in plant cell differentiation.

This book contains two comprehensive articles by two leading authorities in the chemistry and biochemistry of lignin and its precursors. The chapters are clearly written, easy to read and extremely well documented. The information is summarized by clear diagrams and tables. This slim monograph presents a complete survey of the present ideas about the structure and biochemistry of lignin. At the same time it traces the growth of the ideas and concepts against the experimental background which produced them. This is a very impressive feat by the authors and the editors; they are to be warmly congratulated for producing this very important book that is suitable for advanced students and research workers in botany, plant biochemistry and chemistry.

D. H. NoRThcote

\section{PLANT CELL ANATOMY}

\section{Plant Anatomy}

Experiment and Interpretation. Part 1. Cells and Tissues. By Elizabeth G. Cutter. (Series of Student texts in Contemporary Biology.) Pp. vii +168 . (Arnold: London, April 1969.) $48 s$ boards; $24 s$ paper.

Thrs book is described as a student textbook of plant anatomy and represents a careful selection of the characteristics of each of the cell types found in plants, together with aspects of their development. The approach is essentially a developmental one, stressing classical and modern experimental evidence where possible, and therefore the information is presented in a livelier way than the usual textbook list of cell types. The relationships between structure and function indicated and the suggestions of areas where further research is necessary provide an impression of a continuing endeavour with living materials rather than the dead herbarium specimen.

No cell types are omitted and the result is a competent concise survey of the plant corpus, with a good list of textbooks for further reading and a comprehensive reference list of the experiments cited. Botanical nomenclature tends to be unnecessarily detailed and the author does occasionally tend to catalogue, for example, eleven stomatal names and five sclereid terms. Fortunately, the uncategorized diversity within a common developmental framework is usually stressed.

The illustrations are frequent and the excellent simple line drawings are in effective contrast to the complexity of the well chosen light and electron micrographs which are both very well reproduced here.

This synthesis of the classical light microscope work with recent electron microscope studies elegantly clarifies the current ideas of plant development and of the possible correlation between structure and function in plant cells. A brief account of the role of auxins in differentiation of the cell types is included and makes the book an extremely useful text for introductory interdisciplinary university courses of the cell biology type.

F. B. P. Wooding

\section{OSCILLATING PHENOMENA}

\section{Rhythmic Phenomena in Plants}

By B. M. Sweeney. (Experimental Botany: an International Series of Monographs.) Pp. ix +147 . (Academic Press: London and New York, March 1969.) 47s 6d; $\$ 7$.

As Dr Sweeney has stated in her preface, this is a book about one half of a subject, and it therefore starts off at a tremendous disadvantage. The wisdom of confining such a book to plants, and of omitting almost all the important recent work on animal systems, is no doubt clear in the minds of the publishers, but it has deried the reader an account of the now very important practical implications of circadian rhythmicity in diagnostic and therapeutic medicine, in the sociological and behavioural sciences, and in commerce. Despite this disadvantage, the author has succeeded in producing a useful introductory account of the many different types of oscillating phenomena to be found in plants at all levels of organization from the unicellular algae to the angiosperms. No other book has attempted to deal with the whole spectrum of rhythms in which the periods range from a few minutes to a year or more. The book's main function will be to introduce to the reader the concept that the behaviour and biochemistry of an organism kept under uniform environmental conditions is as likely to be eyclic as steady. Furthermore, it should emphasize that an clementary treatment of circadian and other period. icities must form a part of any course in biology, regardless of whether the emphasis is on plants, animals or microorganisms.

The book is balanced, well written, easily read, and well indexed. The choice and quality of illustrations are excellent. The introductory chapter dealing chiefly with the work completed in the past century serves to remind us of how far our knowledge in this field has advanced with the development of modern techniques. There are a few minor mistakes such as the incorrect spelling of the names of Zinn and Bünning on pages 1 and 50 respectively, the incorrect labelling of the abscissa of figure 3.5 , in which time of day is expressed as $m \mu$, and the substitution of foot-candles for lux as the units of illumination in lines 1 and 3 on page 39 .

The chief merit of this book is that it provides a great deal of factual information about rhythmic phenomena in plants without using the most impossible and largely useless jargon which has been introduced into this subject over the past 20 years. I hope that the efforts of Dr Sweeney will be rewarded by a greater interest being taken in plant rhythms and their underlying mechanisms. Intrinsically, these descrve more attention, for as control mechanisms go, there can be few that pose more challenging problems.

MaLCOLM B. WilkiNs

\section{MOLLUSC TREATISE}

\section{Traité de Zoologie}

Anatomie, Systématique, Biologique. Publié sous la direction de Pierre-P. Grassé. Tome V: Mollusques, Gastéropodes et Scaphopodes, Fasc. III. Pp. 1084+11 plates. (Masson et Cie: Paris, 1968.) 280 francs.

THrs volume deals with gastropod molluses and with scaphopods, according to the title page, but there is also 